\title{
The Influence of Robots on Students' Computational Thinking: A Literature Review
}

\author{
Kaiqin Yang, Xin Liu, and Guang Chen
}

\begin{abstract}
With the rapid development of information technology and the further expansion of its social influence, robot technology has gradually matured. In this stage, cultivating students' computing thinking has become an important task to promote the development of information technology talents and an essential direction of information technology education. Robotic is an excellent tool for introducing coding and computational thinking into early childhood education. How to cultivate students' computational thinking and how to use a robot to realize the transformation of learning is very important. Based on this, this paper systematically reviews the influence of robot teaching on students' computational thinking in k-12 education and looks forward to the future development direction of research on computational thinking and optimization of robot education.
\end{abstract}

Index Terms-Computational thinking, robot education.

\section{INTRODUCTION}

Computational thinking is an important concept which is widely concerned in the international computer field. This ability to think like a computer scientist is defined as computational thinking. According to Wing, "computational thinking involves solving problems, designing systems, and understanding human behavior by utilizing the basic concepts of computer science." Computational thinking is a valuable skill for all learners. It can be applied to everyday problem-solving activities as well as many other areas of learning. Zhou Yizhen believes that learning computational thinking is the need for innovation in the information society. Just as everyone has the ability of "reading, writing, and calculating" (3R for short), computational thinking is a necessary thinking ability [1].

Jaipal-jamani \& Angeli found teaching with robots could increase students' interest in learning new technologies. [2] And they also enhance their understanding of basic scientific concepts and improve their computational thinking. For the cultivation of computational thinking, programming education is an effective way to cultivate students' computational thinking. It has unique advantages in the cultivation of students' computational thinking and is conducive to the cultivation of students' problem analysis ability and problem-solving ability. Moreover, the coding process can also improve students' cognitive and social-emotional skills. [3] In programming education, robot

Manuscript received December 25, 2019; revised March 18, 2020. This work was supported in part by Beijing Normal University, China.

Kaiqin Yang, Xin Liu, and Guang Chen are with Beijing Normal University, China (e-mail: 17610249581@163.com, 1063452463@qq.com, guang@drgchen.com). education is integrated into the link of students' hands-on construction. So that students can acquire skills of using hands-on tools and enhance their hands-on ability [4].

In recent years, people's interest in robotics has been increasing. [5] Currently, more and more countries have incorporated programming courses into the national curriculum system. Therefore, it is very important to make good use of programing robots, design, and develop a series of courses based on educational robots effectively. It will cultivate the thinking ability of primary and secondary school students. In recent ten years, the number of relevant studies on computational thinking has been increasing. This study explores the influence of robot education on computational thinking in the existing literature.

\section{METHODS}

In this study, snowball rolling method was selected. Snowballing is a method of literature review proposed by Wohlin et al. in 2014. [6] It refers to searching references and citations of literature that have been collected, screening eligible literature until it is difficult to use backward and forward snowballing in iteration to find new papers and end the snowballing cycle. The steps to snowball are as follows:

Step 1 Start set: identify keywords and formulate search strings.

Step 2 Backward snowballing: using the reference list to identify new papers to include.

Step 3 Forward snowballing: identifying new papers based on those papers citing the paper being examined.

This study developed the following inclusion criteria to determine which documents could be included in this review.

1) The article was published in the Social Sciences Citation Index journal.

2) The article is an empirical study.

3) Studies which published from 2009 to 2019.

4) Research measures the changes in students' computational thinking.

\section{A. Keyword Search}

Using the search strings "computational thinking" and "robot*" as keywords, the two researchers, searched the Web of Science database for as many related literatures as possible from 2009 to 2019 and returned 47 papers. The two researchers analyzed the titles and abstracts of the papers, respectively, and determined whether they met the criteria for inclusion in the literature review. If there was any doubt about the retention of the study, the two researchers independently reviewed the full text and then made the final decision together. Results 10 papers were selected. 


\section{B. Snowballing Approach}

After the keyword search, the first round of the snowball method was adopted to search the papers in Web of Science. At the end of the search, 530 references from backward snowball and 144 references from forwarding snowball were found. Four new papers were selected based on the four inclusion criteria.

In the second round of snowballing, no new qualified papers were selected. After two rounds of snowballing, it is difficult to find more papers that meet the criteria, and the number of duplicate papers is increasing (see Table I). This indicates that the iteration of the snowball method can be completed.

Finally, 14 papers were selected as samples for subsequent literature review, as shown in Table I (see the Appendix A for specific literature).

\begin{tabular}{ccc} 
TABLE I: SUMMARY OF KEYWORD SEARCH AND SNOWBALLING APPROACH \\
\hline \hline $\begin{array}{l}\text { Selection } \\
\text { strategy }\end{array}$ & $\begin{array}{c}\text { Papers resulting } \\
\text { from the search }\end{array}$ & Selected \\
\hline Keyword search & 47 & 10 \\
$\begin{array}{c}\text { First-round } \\
\text { snowballing } \\
\text { approach } \\
\begin{array}{c}\text { Second-round } \\
\text { snowballing } \\
\text { approach } \\
\text { total }\end{array}\end{array}$ & 674 & 4 \\
\hline \hline
\end{tabular}

\section{RESULTS}

\section{A. Descriptive Analysis}

Fig. 1 shows the distribution of the publication time of 14 literatures. It can be known from Fig. 1 that SSCI empirical research related to the keyword "computational thinking" and "robot*" only appeared in 2014. In the past ten years, the year with the largest number of related literature published was 2019 , accounting for about $50 \%$ of the total number of articles published in the past ten years.

As can be seen from the time distribution of the literature published between 2009 and 2019, the academic community began to pay attention to the research on the relationship between robots and computational thinking since 2019 and devoted itself to providing a research basis for robots as an important means of cultivating students' computational thinking.

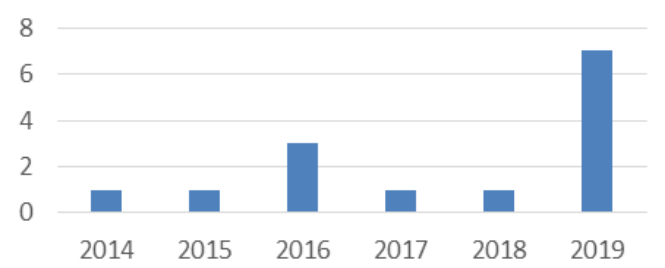

Fig. 1. The distribution of reviewed articles from 2009 to 2019 (grade level distribution of the research study).

Participants in the 14 literatures ranged in age from pre-school children, primary school students, middle school students, high school students, and college students (normal university students). As shown in Fig. 2, the oldest sample group in the 14 literatures is college students, while the youngest sample group is pre-school children. The largest sample group was pre-school children, with 6 articles (35\%). Of the six articles, five were published in 2019. From the number of publications, it can be inferred that pre-school children have become the focus of research related to "using robots to cultivate computational thinking" in recent years. Studies have shown that children using robotics can acquire high levels of coding and computational thinking skills [7].

This may be because robots are better suited to nurturing pre-school children's computational thinking. [8] According to Piaget's cognitive development stage theory, children aged 2-7 are in the pre-operational stage, and children in this stage have the characteristics of symbolic thinking and intuitive thinking. Children's thinking has a certain specific image.

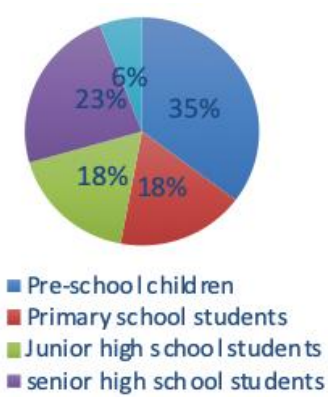

Fig. 2. The proportion of grade level (type of robot used).

The 14 literatures also use a wide range of robot types, including TangibleK Robotic, LEGO Robotic, KIBO Robotic, bee-bot Robotic, Virtual and Physical Robotic, An ultra-low-cost line follower Robotic, Arduino+scratch Robotic (Fig. 3).

These six kinds of robots can be called a relatively mature educational resource. In the 14 studies, the most used robot is LEGO Robotic, which is applied to students of all ages to cultivate their computational thinking. This is mainly due to the fact that LEGO has different sets of models to suit the needs of students of different ages. Research has shown that LEGO robotics is widely used in k-8 environments to improve children's problem-solving skills and enhance their understanding of scientific applications and concepts [9].

The second is KIBO Robotic and bee-bot Robotic, both of which are used in preschool children's classes. This may be due to the cute appearance and soft texture of KIBO Robotic and bee-bot Robotic, which are more in line with the learning characteristics of young preschool children. [10] Moreover, the robot is easy to operate and does not require a computer, making it an attractive choice for children to program robots [11].



Fig. 3. The proportion of grade level (the influence of robot teaching on students' computational thinking). 
The results of 14 studies show that using robots as teaching tools can effectively improve students' thinking ability. Even among preschool children aged 3-6, the use of robots can also promote the development of their computational thinking. Among them, Leonard, $\mathrm{J}$ et al. have shown that adopting appropriate teaching methods in the robot course can promote the development of students' computational thinking. [12] When students complete specific tasks, students build knowledge through self-knowledge rather than just accepting knowledge [13].

This may be because the combination of robotics and programming provides a fun and hands-on way for children to effectively achieve integrated STEM education. For example, children can participate in engineering design while using programmed robots, learn mathematics by sorting, estimating, and counting, and learn science by exploring perception and observation [14].

At the same time, the research also shows that although educational robots have advantages in cultivating students' computational thinking, teachers still need to adopt certain teaching support strategies to utilize robot design courses to train students in computational thinking in a way that students can learn and understand.

\section{B. How Should Teachers Integrate Computational Thinking into Robot Courses}

Research shows that the $6 \mathrm{E}$ teaching method is applicable to children in the upper primary school (grade 6) in robotics courses. [15] In 6E, new elements and links were added to the $5 \mathrm{E}$ teaching model. Stephanie Fletcher modified the 5E teaching model and added a new stage in the "explanation" stage. "express" formed the "6E model". Based on the original emphasis on scientific inquiry, this teaching strategy makes it possible to systematically think about problems, comprehensively use interdisciplinary knowledge to analyze problems through engineering practice, reflect on the results of scientific inquiry and construct scientific interpretation by introducing the process of "design and redesign".

The 6E teaching model (Fig. 4) is a middle school learning cycle based on constructivism. Students redefine, regroup, and interpret themselves through interaction with peers and the environment to change their original concepts. [16] In this process, students learn how to build knowledge through discussion, information collection and practical activities to learn how to solve problems purposefully. [17] The learning process of this learning model is similar to that of solving problems through computational thinking, and it is beneficial to enhance the learning effect based on robot activities [18].

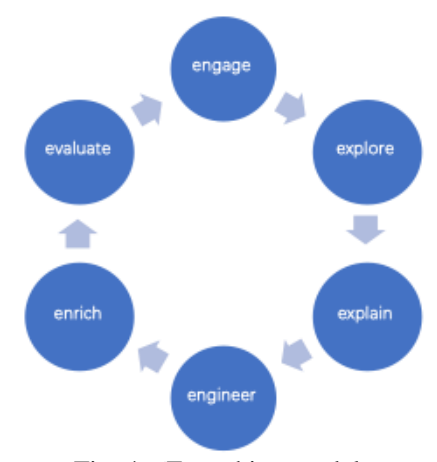

Fig. 4. 6E teaching model.

\section{How to Narrow the Gender Difference between Male} and Female Students' Computational Thinking

According to the literature review, although the robot can reduce the difficulty for children to learn computational thinking. However, some studies have shown gender differences between male and female students when using robots to learn computational thinking. Compared with boys, girls' learning progress is slow. However, the gender gap between boys and girls in computer mind learning can be reduced by robot-assisted instruction. A gender-friendly robotic learning environment suitable for student development will enable both boys and girls to experience a positive experience flow and keep learning.

In addition, studies have shown that children as young as 6 already have gender stereotypes that boys are better at programming and robotics than girls. This may also be the reason why male and female students have gender differences in computational thinking. Designing technology activities that are inclusive and attractive and expanding the appeal of computer science and engineering may benefit more students.

\section{An Evaluation Scale of Computational Thinking Should Be Established}

The implementation results of any teaching need some evaluation methods to test the teaching effect. Similarly, students need an evaluation tool to evaluate the learning effect of calculating thinking. Special computational thinking tools were used in $7(50 \%)$ of the 14 literatures. These assessment tools are scales developed by researchers based on previous research results or calculating the connotation of thinking. Finally, the reliability and validity of the scale will be tested by teaching practice evaluation.

Although computational thinking assessment tools are used in many studies, these assessment tools are a set of tools compiled by researchers themselves, which are not uniform and not widely promoted. In addition, learning outcomes recorded and assessed by assessment tools are problematic due to the lack of validated CT measurement instruments. In general, the lack of indicator system and standardized assessment methods will make the assessment results of students' computational thinking level controversial [19].

\section{CONCLUSION}

Computational thinking is a universal skill that everyone has the potential to learn. Designing appropriate robotics courses to develop computational thinking is still a new field of study, and its popularity is growing. This study combed through the contents of 14 core journal literatures on robotics and computational thinking in the Web of Science database from 2009 to 2019. The results show that the core journal of computational thinking and robotics has only appeared since 2014. By 2019, the number of relevant literature has increased dramatically, with a total of 7 papers.

In addition, in terms of research objects, it covers all academic segments from kindergarten to university. The 14 studies used six types of robots: LEGO Robotic, KIBO Robotic, bee-bot Robotic, Virtual and Physical Robotic, An ultra-low-cost line follower Robotic, Arduino+scratch 


\section{Robotic.}

The most used robot is LEGO Robotic, which is applied to students of all ages. At the same time, the research results of 14 kinds of literature all prove that students' computing thinking can be cultivated with the help of robot classroom. The support strategy used by teachers in the process of teaching with the help of robots also plays an important role in promoting the development of students' computational thinking. At the same time, computational thinking can also improve the gap between male and female students in computational thinking, scientific learning, and technical learning.

According to the above research results, we discuss the $6 \mathrm{E}$ model applicable to the course of robot-computational thinking. It also advocates the establishment of special computational thinking evaluation tools. A good and appropriate assessment tool is beneficial for researchers to further explore methods and tools suitable for students' computational thinking development. In the face of the current lack of scientific and unified computational thinking evaluation tools, the establishment of computational thinking evaluation tools is extremely urgent. More research is needed in this area to discover the potential of robots in computational thinking education.

\section{APPENDIX}

\begin{tabular}{|l|l|c|}
\hline Robot type & Author & $\begin{array}{l}\text { Whether it has a } \\
\text { positive impact on } \\
\text { computational } \\
\text { thinking }\end{array}$ \\
\hline $\begin{array}{l}\text { Virtual and } \\
\text { Physical Robotic }\end{array}$ & Berland\&Wilensk, 2015 & \multicolumn{1}{|c|}{ Yes } \\
\hline KIBO Robotic & $\begin{array}{l}\text { Bers,2019; } \\
\text { González-González,2019 }\end{array}$ & \multicolumn{1}{|c|}{ Yes } \\
\hline LEGO Robotic & $\begin{array}{l}\text { Atmatzidou, 2016; } \\
\text { Leonard at al.,2017; } \\
\text { Atmatzidou, 2016; } \\
\text { Leonard, 2016; } \\
\text { Jaipal-Jamani, 2017; } \\
\text { Bers,2014 }\end{array}$ \\
\hline $\begin{array}{l}\text { Bee-bot Robotic } \\
\text { Mungeli, 2019; } \\
\text { Eben.B, 2017 }\end{array}$ & \\
\hline $\begin{array}{l}\text { An ultra-low cost } \\
\text { line follower } \\
\text { Robotic }\end{array}$ & Pérez, 2019 & Yes \\
\hline Arduino+scratch & Hsiao, 2019 & Yes \\
\hline
\end{tabular}

\section{CONFLICT OF INTEREST}

My co-authors and I declare no competing interests.

\section{AUTHOR CONTRIBUTIONS}

My co-authors have all contributed to this manuscript and approve of this submission.

\section{REFERENCES}

[1] C. Angeli et al., "A K-6 computational thinking curriculum framework: implications for teacher knowledge," Journal of Educational Technology \& Society, vol. 19, no. 3, pp. 47-57, 2016.

[2] K. Jaipal-Jamani and C. Angeli, "Effect of robotics on elementary preservice teachers' self-efficacy, science learning, and computational thinking," J. Sci. Educ. Technol., vol. 26, no. 2, pp. 175-192, Apr. 2017.
[3] M. U. Bers, C. González-González, and M. B. Armas-Torres, "Coding as a playground: Promoting positive learning experiences in childhood classrooms," Computers \& Education, vol. 138, pp. 130-145, Sep. 2019.

[4] D. Chen, Z. Li, and T. Wang, "Exploration and practice: A competition based project practice teaching mode," Mechatronics, vol. 24, no. 2, pp. 128-138, Mar. 2014

[5] F. B. V. Benitti, "Exploring the educational potential of robotics in schools: A systematic review," Computers \& Education, vol. 58, no. 3, pp. 978-988, Apr. 2012.

[6] C. Wohlin, "Guidelines for snowballing in systematic literature studies and a replication in software engineering," in Proc. 18th International Conference on Evaluation and Assessment in Software Engineering, New York, NY, USA, 2014, pp. 38:1-38:10.

[7] M. U. Bers, C. González-González, and M. B. Armas-Torres, "Coding as a playground: Promoting positive learning experiences in childhood classrooms," Computers \& Education, vol. 138, pp. 130-145, Sep. 2019.

[8] J. Piaget, "The psychology of intelligence and education," Childhood Education, vol. 42, no. 9, pp. 528-528, May 1966.

[9] T. Karp and P. Maloney, "Exciting young students in grades k-8 about STEM through an afterschool robotics challenge," American Journal of Engineering Education, vol. 4, no. 1, pp. 39-54, 2013.

[10] A. G.-V. Muñoz-Repiso and Y.-A. Caballero-González, "Robotics to develop computational thinking in early childhood education," Comunicar: Media Education Research Journal, vol. 27, no. 59, pp. 63-72, 2019.

[11] Y. A. C. González and A. G.-V. Muñoz-Repiso, "Development of computational thinking and collaborative learning in kindergarten using programmable educational robots: A teacher training experience," in Proc. 5th International Conference on Technological Ecosystems for Enhancing Multiculturality, New York, NY, USA, 2017, pp. 5:1-5:6.

[12] J. Leonard et al., "Using robotics and game design to enhance children's self-efficacy, STEM attitudes, and computational thinking skills," J. Sci. Educ. Technol., vol. 25, no. 6, pp. 860-876, Dec. 2016.

[13] L. D. Dierking, J. H. Falk, L. Rennie, D. Anderson, and K. Ellenbogen, "Policy statement of the 'informal science education' ad hoc committee," Journal of Research in Science Teaching, vol. 40, no. 2, pp. 108-111, 2003.

[14] E. R. Kazakoff, A. Sullivan, and M. U. Bers, "The effect of a classroom-based intensive robotics and programming workshop on sequencing ability in early childhood," Early Childhood Educ J., vol. 41, no. 4, pp. 245-255, Jul. 2013.

[15] H.-S. Hsiao, Y.-W. Lin, K.-Y. Lin, C.-Y. Lin, J.-H. Chen, and J.-C. Chen, "Using robot-based practices to develop an activity that incorporated the 6e model to improve elementary school students' learning performances," Interactive Learning Environments, pp. 1-15, Jun. 2019.

[16] B. N. Burke, "The ITEEA 6E learning bydesign (TM) model maximizing informed design and inquiry in the integrative STEM classroom," Technology and Engineering Teacher, vol. 73, no. 6, pp. 14-19, Mar. 2014.

[17] M. U. Bers, C. González-González, and M. B. Armas-Torres, “Coding as a playground: Promoting positive learning experiences in childhood classrooms," Computers \& Education, vol. 138, pp. 130-145, Sep. 2019.

[18] S. Atmatzidou, S. Demetriadis, and P. Nika, "How does the degree of guidance support students' metacognitive and problem solving skills in educational robotics?" J. Sci. Educ. Technol., vol. 27, no. 1, pp. 70-85, Feb. 2018.

[19] A. Master, S. Cheryan, A. Moscatelli, and A. N. Meltzoff, "Programming experience promotes higher STEM motivation among first-grade girls," Journal of Experimental Child Psychology, vol. 160, pp. 92-106, Aug. 2017.

Copyright $(C) 2020$ by the authors. This is an open access article distributed under the Creative Commons Attribution License which permits unrestricted use, distribution, and reproduction in any medium, provided the original work is properly cited (CC BY 4.0).

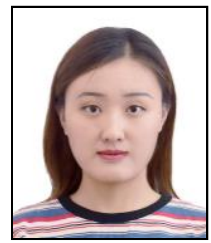

Kaiqin Yang was born in Jilin, China, on August 1, 1995.

She is currently a master student of education at Beijing Normal University. Her main areas of research are robotics education and STEM education. 


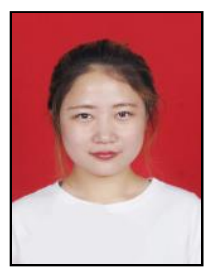

Xin Liu was born in Shanxi, China, on October 4, 1995

She is currently a master student of education at Beijing

Normal University. Her main area of research is the

science education of preschool children.

conferences and workshops. He has published more than 50 journal articles, book chapters and Conference papers. His current research interest is cognitive development in information age and smart learning environments.

Dr. Chen is the leader of a National Social Science Fund project, a Beijing Municipal Commission of Education Fund project, and more than 10 other research projects.

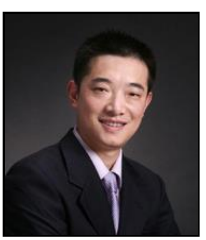

Guang Chen was born in Beijing, China. He received his $\mathrm{PhD}$ degree in developmental and educational psychology from School of Psychology, Beijing Normal University.

$\mathrm{He}$ is an assistant professor in the School of Educational Technology, Faculty of Education, Beijing Normal University. He is a reviewer of several SSCI journals and PC member of more than 10 international 